\title{
Further tests of the scarcity and luxury hypotheses in dispositional greed: Evidence from two large-scale Dutch and American samples
}

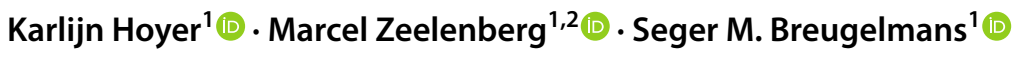

Accepted: 1 November 2021

(c) The Author(s) 2021

\begin{abstract}
A recent, large-scale study among Chinese adolescents found that childhood socioeconomic status (CSES) was positively related to dispositional greed (i.e., the "luxury hypothesis"), instead of negatively related (i.e., the "scarcity hypothesis"; Liu et al., 2019c). This relationship was found for only-children, not for children with siblings. The generalizability of these findings may be limited, due to China's one-child policy and socioeconomic policies which may have led to fewer differences in wealth. We replicated this research in two other cultural contexts that represent markedly different socioeconomic policies in order to test its generalizability: the Netherlands (Study 1, $N=2367,51.3 \%$ female, $M_{\text {age }}=54.06, S D=17.90$ ), and the USA (Study 2, $N=999,50.1 \%$ female, $M_{\mathrm{age}}=33.44, S D=12.28$ ). Hierarchical multiple regressions were conducted to test the association between CSES and greed. We mostly replicated the findings by Liu et al. (2019c): CSES was positively related to greed in both studies ("luxury hypothesis") and there was a moderating effect of siblings in Study 1, but not in Study 2. Implications for theories on greed as well as future research on the association between CSES and greed are discussed.
\end{abstract}

Keywords Dispositional greed $\cdot$ Childhood socioeconomic status $\cdot$ Family size $\cdot$ Replication

Greed, the dissatisfaction with what one currently has, combined with the desire to acquire more, is ubiquitous but also evaluated in opposing ways. On the one hand, greed is considered to be an important motivation behind economic growth and prosperity (Greenfeld, 2001); on the other hand, it is considered a sin because of its negative societal outcomes (Bloch, 1984; Tickle, 2004). Individual differences in greed can be reliably measured by the Dispositional Greed Scale (DGS, Seuntjens et al., 2015), and by various other scales (Zeelenberg et al., 2021). Dispositional greed has been associated with various psychological and economic factors as well as negative outcomes (Hoyer et al., 2021; Zeelenberg et al., 2020). Greedy people are morally less sensitive, tend to behave

Karlijn Hoyer

K.Hoyer@tilburguniversity.edu

1 Tilburg Institute for Behavioral Economic Research \& Department of Social Psychology, Tilburg University, PO Box 90153, 5000, LE, Tilburg, The Netherlands

2 Department of Marketing, Vrije Universiteit Amsterdam, Amsterdam, Netherlands more unethically, find various transgressions more acceptable, and are more corrupt (Li et al., 2021; Seuntjens et al., 2019; Zhang \& Xiang, 2021). In addition, they display more psychological entitlement, less empathy, less concern for others and egoism, higher spendthrift, less selfcontrol and higher buying impulsivity; they take more money in dictator and ultimatum games, and contribute less in resource dilemmas (Krekels \& Pandelaere, 2015; Li et al., 2019; Seuntjens et al., 2015). Greedy adolescents spend more, save less, and have more debt (Seuntjens et al., 2016). Greed is related to emotional instability, lower self-esteem, and lower life satisfaction (e.g., Liu et al., 2019a; Seuntjens et al., 2015). To summarize, dispositional greed has been associated with many negative outcomes both to people themselves and to others. For these reasons, it is important to understand how individual differences in greediness come about.

Research has shown that many psychological characteristics that are acquired during adolescence, are typically maintained in adulthood (Eccles et al., 2013). It turns out that a key predictor of several adult personality traits is how poor or wealthy people grew up, and this factor is often expressed in terms of Childhood Socioeconomic Status (CSES; Griskevicius et al., 2011). For example, 
CSES relates to how much people spend and save as adults (Griskevicius et al., 2013). As a consequence, it seems likely that CSES also relates to how greedy people are later in life. This has indeed been proposed (e.g., Chen, 2018; Krekels, 2015; Poluektova et al., 2015), but there are different views on how exactly this relationship should pan out.

Liu et al. (2019c) noted that on the basis of observed findings in the literature, two opposing hypotheses could be formulated on the relation between growing up rich or poor on the one hand, and the level of greed in adulthood on the other. First is the Scarcity hypothesis, implying that CSES negatively predicts greed. This hypothesis is based on findings of Krekels (2015) and Chen (2018) that children who grew up in disadvantaged environments were greedier in adulthood.

In a study with 198 Amazon MTurk workers, Krekels (2015, p. 62) assessed "childhood and current SES, childhood and current support systems, childhood harsh environments and current uncertainty in life to examine whether there are links between life situations during upbringing and adulthood on the one hand and a greedy disposition on the other hand" and correlated these constructs to Krekels and Pandelaere's (2015) DGS scale. Out of the 17 constructs measured, 6 correlated with dispositional greed (Krekels, 2015, Appendix A on page 87-88; not correcting for multiple testing). These were mother's education $(r=-.19$, $p<.01)$, mother's job $(r=-.18, p<.05)$, subjective ranking $(r=-.18, p<.05)$, childhood monetary support $(r=-.21$, $p<.01)$, the occurrence of harsh unpredictable childhood environments $(r=.19, p<.01)$, and current feelings of uncertainty $(r=.24, p<.001)$.

In a sample with 364 Chinese college students, Chen (2018) examined the relation between dispositional greed (measured via the 7-item-DGS by Seuntjens et al., 2015, the 7-item Greed Trait Measure by Mussel et al., 2015, and the 10-item Greed Subscale of the Virtues and Vices Scale of Veselka et al., 2014), childhood environmental unpredictability (measured using the 5-item Environmental Conditions Scale of Brumbach et al., 2009, and the 3-item Childhood Unpredictability Scale of Mittal et al., 2015), and insecure attachment (measured by Armsden \& Greenberg's, 1987 Inventory of Parent and Peer Attachment, that has 5 items for each parent). Chen (2018) found that all three greed scales correlated positively with both childhood unpredictability and both insecure attachment scales ( $r$ s between .25 and .37). In the words of Chen (2018, p. 76), this suggests that "greed is a life history strategy adopted in response to an unpredictable environment".

The Luxury hypothesis, the opposing hypothesis about how growing up rich or poor is related to greed in adulthood, implies that CSES positively predicts greed. This hypothesis is based on the findings of Poluektova et al. (2015) and
Lea et al. (1995). Poluektova et al. (2015) found in a study among poor $(N=157)$ and non-poor $(N=140)$ residents of Moscow, that Griskevicius et al.'s (Griskevicius et al., 2011) CSES scale related positively $(r=.24 . p<.05)$ to Seuntjens et al.'s (2015) DGS scale, meaning that participants who remembered being better off in their childhoods also were greedier in their adult lives. Lea et al. (1995) provided more circumstantial evidence and found that people whose parents were relatively well-off, were more likely to have consumer debt and a more materialistic orientation later in life, suggesting that "early experiences are important in consumers' subsequent debt careers" (p. 697).

Liu et al. (2019c) reasoned that if childhood scarcity or luxury would impact how greedy people are later in life, this relationship might be moderated by the number of siblings people had when growing up. Growing up with siblings means that one has to share the things that one has with others. If growing up poor is associated with being greedy having siblings creates more scarcity, and by having even less, one could become greedier later in life (thus, according to the scarcity hypothesis, the effect of CSES will be strongest for people with siblings). In contrast, if growing up rich is associated with being greedy, having siblings would attenuate this effect. If one has a lot and does not need to share this with siblings, one could become greedier (thus, according to the luxury hypothesis, the effect of CSES will be strongest for people without siblings). Liu et al. (2019c) conducted a large-scale survey with 3440 Chinese middle school students (11-19 years old) from various locations in China to examine these competing hypotheses. They found some support for the luxury hypothesis and not for the scarcity hypothesis: Dispositional greed, as measured by Seuntjens et al.'s (2015) 7-item DGS scale, was positively correlated with growing up wealthy $(r=.04 . p<.05)$, as measured by Griskevicius et al.'s (2011) 3-item CSES scale, for children without siblings. When there was more than one child in a family, no relation between wealth and greed was found.

These initial findings by Liu et al. (2019c) are intriguing and important, but as they themselves argued (p. 38): "The generalizability of the findings of the current study should be tested in different countries." Replication is especially called for because Liu et al. (2019c) collected data in China, which - as a country - has at least two, very specific characteristics that are relevant to the discussion on the Scarcity Hypothesis and the Luxury Hypothesis. First, it is the only country in the world that has structurally implemented a one-child policy. As a result, the largest group of participants in Liu et al.'s (2019c) study had no siblings at all (49.1\%), the second largest group had one sibling $(37.7 \%)$, and only $13.2 \%$ percent of the participants had more than one sibling. Hence, Liu et al. 
Table 1 Descriptive statistics and correlations among childhood socioeconomic status, number of siblings, dispositional greed, gender and age $(N=2367$ Dutch adults $)$ in study 1

\begin{tabular}{llllllll}
\hline & Range & $M$ & $S D$ & CSES & \#Siblings & Greed & Gender \\
\hline CSES $(\alpha=.82 ; \omega=.82)$ & $1-7$ & 3.83 & 1.35 & - & & & \\
Number of siblings & $0-20$ & 2.65 & 2.29 & $-.16^{* *}$ & - & & \\
Greed $(\alpha=.90 ; \omega=.92)$ & $1-5$ & 2.05 & 0.71 & $.09^{* *}$ & $-.13^{* *}$ & - & \\
Gender $(51.3 \%$ female) & $0-1$ & & & -.03 & -.01 & $.14^{* *}$ & - \\
Age (in years) & $16-95$ & 54.06 & 17.90 & $-.26^{* *}$ & $.33^{* *}$ & $-.37^{* *}$ & $.05^{*}$ \\
\hline
\end{tabular}

$* p<.05, * * p<.001$. Greed was assessed with the DGS (Seuntjens et al., 2015), and CSES with the Childhood-SES scale (Griskevicius et al., 2011). Gender is coded, $0=$ female, $1=$ male (2019c) only used two categories in their analyses: participants with siblings and participants without siblings. This dichotomy may not do justice to the effects of having more siblings on adult greed, both for the luxury hypothesis and for the scarcity hypothesis. As resources get shared among more siblings in a continuous fashion, one might expect a continuous moderation, which Liu et al. (2019c) could not test for because of the specific characteristics of their Chinese sample.

A second reason for testing the generalizability of Liu et al.'s (2019c) findings is that China has long been a communist country. Only relatively recently wide-spread private property and private ownership of companies have been introduced. Thus, substantial differences in wealth among the population are relatively recent and uncommon. This may have had consequences for the way Liu et al.'s (2019c) participants rated their Childhood-SES, which explicitly asks about relative status of one's family compared to others.

In short, because we find Liu et al.'s (2019c) findings important, we think that the specific Chinese context of their study warrants replications in other contexts. Thus, we set out to closely replicate it in two countries that have a larger variety in the number of siblings and a longer history of capitalism, The Netherlands (Study 1) and the United States of America (Study 2), also using large samples. Please note that these two countries were chosen because they allowed us to gather data in a close replication of Liu et al. (2019c) in contexts that differed on the key issues from China. They were not chosen because they are more or less representative of the world's population for which a more extensive and systematic sampling of countries would be needed. Because we initially had no theoretical reason to favor one hypothesis over the other, the first study was exploratory. For the second study we preregistered (https://aspredicted.org/3a4s4.pdf) that we expected support for the luxury hypothesis, that is, a positive correlation between CSES and greed. We report for both studies all data exclusions, all manipulations, and all measures. The materials, data, and code for both studies can be found on https://researchbox.org/177.

\section{Study 1}

\section{Method}

Participants were members of the LISS-panel (Longitudinal Internet Studies for the Social Sciences, for more information www.lissdata.nl), a representative panel of the Dutch population ( $N=2367,51.3 \%$ female). Participant ages ranged from 16 to 95 years old $\left(M_{\text {age }}=54.06, S D=17.90\right)$. Prior to the analyses, we excluded 50 participants who did not complete all relevant items of the survey (i.e., the DGS, CSES and the item on family size). Roughly half of the sample filled out the DGS at the beginning of the survey, the other half at the end (and there were no order effects ${ }^{1}$ ). The survey included the following three elements: the 7-item DGS, the 3-item CSES and the 1-item on family size. Participants also responded to some other questions that were for another project concerning prosocial motivation. The survey was administered in Dutch.

As in Liu et al. (2019c), the key dependent measure was the 7-item DGS (Seuntjens et al., 2015). Example items are: "I always want more", and "It doesn't matter how much I have, I'm never completely satisfied" (rated on five-point Likert scales). As in Liu et al. (2019c), the key predictor variable was the CSES scale (Griskevicius et al., 2011). The three items were: "My family usually had enough money for things when I was growing up", "I grew up in a relatively wealthy neighborhood", and "I felt relatively wealthy compared to the other kids in my school" (rated on sevenpoint Likert scales). The moderator variable was the number of siblings $(M=2.65, S D=2.29)$, what Liu et al. (2019c) refer to as family size. This was measured with the question: "How many older [younger] brothers [sisters] do you have?" Participants were instructed to include deceased brothers and sisters. The distribution was as follows: $6.5 \%$ had 0 siblings; $30.6 \%$ had 1 sibling; $24.7 \%, 2 ; 13.2 \%, 3 ; 8.7 \%, 4$; $6.0 \%, 5 ; 3.3 \%, 6 ; 2.5 \%, 7$; and $4.6 \%$ more than 8 siblings.

\footnotetext{
1 The difference between filling out the DGS at the beginning of the survey $(M=2.03, S D=0.71)$ and at the end of the survey $(M=2.06$, $S D=0.70)$ was non-significant, $F(1,2365)=0.87$ and $p=.351$.
} 
Table 2 Hierarchical regression analysis of number of siblings and childhood socioeconomic status (CSES) and their interaction (step 2) on dispositional greed ( $N=2367$ Dutch adults) in study 1

\begin{tabular}{lll}
\hline & \multicolumn{2}{l}{$\begin{array}{l}\text { Dependent Variable }=\text { Dispositional } \\
\text { Greed }\end{array}$} \\
\hline Predictors & Step 1 & Step 2 \\
Constant & $2.05^{*}(0.01)$ & $2.04^{*}(0.01)$ \\
CSES & $0.04^{*}(0.01)$ & $0.04^{*}(0.01)$ \\
Siblings & $-0.04^{*}(0.01)$ & $-0.04^{*}(0.01)$ \\
CSES $\times$ Siblings & & $-0.02^{*}(0.00)$ \\
$R^{2}$ & 0.02 & 0.03 \\
$F$ Statistic & $25.26^{*}$ & $22.57^{*}$ \\
\hline
\end{tabular}

** $p<.001$. Regression coefficients (and standard errors). Greed was assessed with the DGS (Seuntjens et al., 2015), CSES with Childhood-SES scale (Griskevicius et al., 2011)
We tested the competing Scarcity and Luxury hypotheses in a hierarchical multiple linear regression analysis on the relationship between CSES and DGS, moderated by the number of siblings (following the lead of Liu et al., 2019c). In the first step we entered centered CSES and number of siblings; in the second step we added the interaction between centered CSES and number of siblings. Table 2 displays the results of these analyses. CSES positively predicted adult greed, and number of siblings negatively predicted adult greed. Furthermore, we found a negative interaction effect, meaning the relationship between CSES and DGS was moderated by number of siblings. The effect was robust to controlling for gender), but not to controlling for both gender and age (see the analyses in Table 5, in the Appendix). The results of simple slope analyses (see right panel of Fig. 1) showed a significant effect of the CSES on
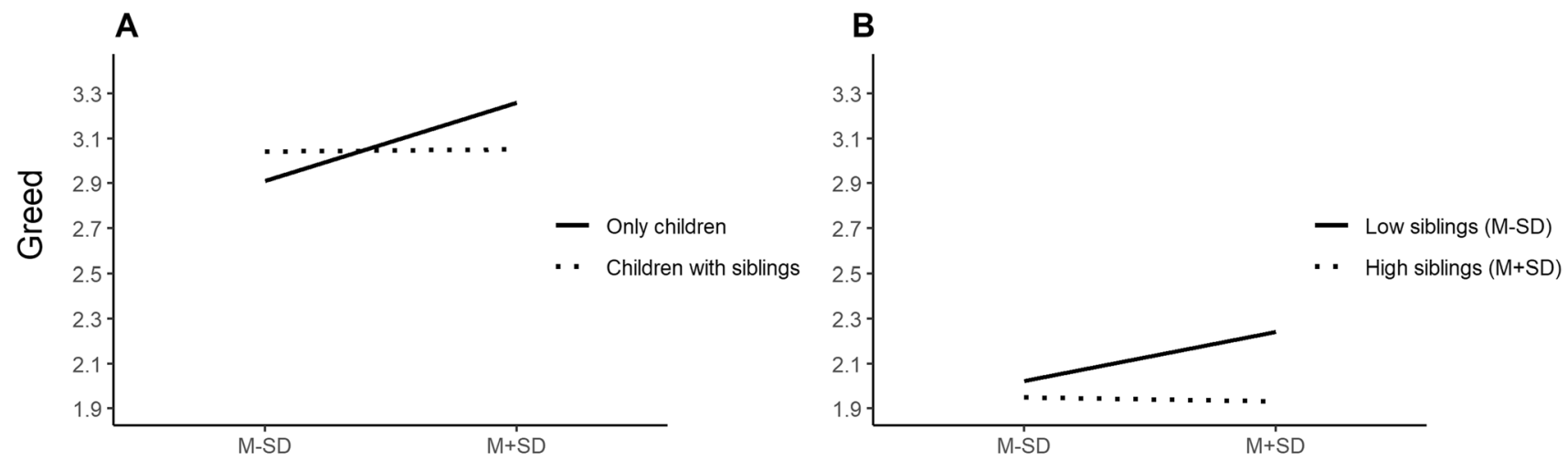

Childhood socioeconomic status

Fig. 1 Results from A: Liu et al. (2019c) and B: study 1 that show the moderating effect of family size on the relationship between CSES and greed

\section{Results and Discussion}

The results of Study 1 are in line with the luxury hypothesis. Table 1 presents the descriptive results and correlations among the variables. As in Liu et al. (2019c), Childhood Socioeconomic Status (CSES) was positively related to greed. We note that this correlation is rather small, and should be interpreted carefully. Our data also revealed a significant negative correlation between CSES and the number of siblings (i.e., family size), that was also present in the data of Liu et al. (2019c). In addition, the results also showed that males were greedier than females, and that greed was negatively correlated with age, findings that are reported more often (e.g., Krekels \& Pandelaere, 2015; Liu et al., 2019c; Seuntjens et al., 2015; Zeelenberg et al., 2020). greed for siblings $1 S D$ below the mean $(b=0.08, S E=0.02$; $t=5.31, p<.001)$, but not for siblings $1 S D$ above the mean $(b=-0.01, S E=0.02 ; t=-0.41, p=.680)$. These findings replicate Liu et al. (2019c); the relation between CSES and dispositional greed is moderated by the number of siblings (i.e., family size).

Figure 1 shows the results from Study 1 next to these obtained by Liu et al. (2019c). The figure not only shows that the results of the regression analyses are very similar. It also shows that the absolute level of greediness is higher in the Chinese sample $\left(M_{\text {only children }}=3.10, M_{\text {children with siblings }}=2.81\right)$ than in the Dutch sample $\left(M_{\text {whole sample }}=2.05\right)$. This could mean a few things. It could be that this is related to the age of the participants. In Seuntjens et al.'s (2016) study with Dutch adolescents, greed scores were also a bit higher $(M=2.40)$. It could also mean that people in China are on 
Table 3 Descriptive statistics and correlations among (childhood) socioeconomic status, number of siblings, dispositional greed, gender and age ( $N=999$ US adults) in study 2

\begin{tabular}{llllllllll}
\hline & Range & $M$ & $S D$ & $N$ & CSES & SES & \#Sibl. & Greed & Gender \\
\hline CSES $(\alpha=.85 ; \omega=.85)$ & $1-7$ & 3.56 & 1.61 & 999 & - & & & & \\
SES $(\alpha=.86 ; \omega=.86)$ & $1-7$ & 3.97 & 1.59 & 999 & $.38^{* *}$ & - & & & \\
Number of siblings & $0-26$ & 1.90 & 1.94 & 999 & $-.10^{*}$ & -.07 & - & & \\
Greed $(\alpha=.86 ; \omega=.90)$ & $1-5$ & 2.50 & 0.88 & 999 & $.24^{* *}$ & $.09^{*}$ & -.03 & - & \\
Gender & $0-1$ & & & 976 & $.13^{*}$ & $.09^{*}$ & $-.08^{*}$ & $.16^{* *}$ & - \\
Age (in years) & $18-89$ & 33.44 & 12.28 & 999 & .01 & $.14^{* *}$ & .01 & $-.11^{* *}$ & .00 \\
\hline
\end{tabular}

$* p<.05, * * p<.001$. Greed was assessed with the DGS (Seuntjens et al., 2015). CSES and SES with the Childhood-SES and the SES scale (Griskevicius et al., 2011). Gender is coded: $0=$ female, $1=$ male average greedier than people in the Netherlands but such interpretations would be conditional upon evidence for fullscore equivalence, which we do not have at the moment (cf. Van de Vijver \& Leung, 1997). Note, however, that the mean greed score of LISS panel participants is relatively low, as was also the case in Seuntjens et al. (2015). Greed scores of Dutch student samples are generally higher (see the studies with Dutch students in: Seuntjens et al., 2015, 2016; Zeelenberg et al., 2020).

A typical Western European phenomenon (also present in the Netherlands) is a demographic decrease in family size over the past decades, meaning that older generations tend to have more siblings than younger generations. This is indeed reflected in the correlation between age and number of siblings, $r(2367)=.33, p<.001$. Hence, we re-examined the effect of family size focusing only on the younger generation (i.e., aged up to and including $35, N=455$ ) and on the older generation (i.e., older than $35, N=1912$ ). For the younger generation, CSES again positively predicted adult greed, but there was no effect of the number of siblings on adult greed, nor was there a significant interaction effect. For the older generation, CSES did not predict adult greed, but there was a negative effect of the number of siblings on adult greed and a negative interaction effect. The results can be found in Table 6, in the Appendix.

\section{Study 2}

Study 2 continues our exploration of the relationship between childhood socioeconomic status and dispositional greed, and it is a further replication of Liu et al. (2019c), this time with a large sample of US American participants. Based on the findings of Liu et al. (2019c), and on the results of Study 1, we expect to find support for the luxury hypothesis, such that CSES positively predicts dispositional greed. We also expect family size to moderate the relationship between CSES and greed. We additionally decided to explore the relationship of current socioeconomic status (SES), with childhood socioeconomic status (CSES) and dispositional greed. This would allow us to see if the relation between CSES and dispositional greed would be robust when controlling for current SES.

\section{Method}

We recruited 1000 U.S. participants via Prolific. One participant did not fill out the DGS and was excluded from analysis, leaving a final sample of $N=999$ (50.1\% female, $2.3 \%$ other). Participant ages ranged from 18 to 89 years old $\left(M_{\text {age }}=33.44, S D=12.28\right)$.

The survey included the same three elements from Study 1 (the 7-item DGS, the 3-item CSES and the 1-item on family size), plus an additional 3-item SES scale (Griskevicius et al., 2011). As in Liu et al. (2019c) and in Study 1, the dependent measure was the 7-item DGS rated on five-point Likert scales (Seuntjens et al., 2015), the key predictor variable was the 3-item CSES scale rated on seven-point Likert scales (Griskevicius et al., 2011), and the moderator variable was the number of siblings $(M=1.90, S D=1.94)$. The distribution was as follows: $13.5 \%$ had 0 siblings; $37.0 \%$ had 1 sibling; $25.8 \%, 2 ; 12.1 \%, 3 ; 5.2 \%, 4 ; 2.8 \%, 5 ; 1.5 \%, 6$; $0.7 \%, 7$; and $1.3 \%$ more than 8 siblings. The additional SES scale had the following three items: "I have enough money to buy things I want", "I don't need to worry too much about paying my bills", and "I don't think I'll have to worry about money too much in the future." (rated on seven-point Likert scales).

\section{Results and Discussion}

Table 3 presents the descriptive results and correlations among the variables. As in Liu et al. (2019c) and in Study 1, Childhood Socioeconomic Status (CSES) was positively 
Table 4 Hierarchical regression analysis of number of siblings and childhood socioeconomic status (CSES), their interaction (step 2) and current socioeconomic status (SES) (step 3) on dispositional greed ( $N=999$ US adults) in study 2

\begin{tabular}{llll}
\hline \multirow{2}{*}{ Predictors } & \multicolumn{3}{l}{ Dependent Variable $=$ Dispositional Greed } \\
\cline { 2 - 4 } & Step 1 & Step 2 & Step 3 \\
\hline Constant & $2.50^{*}(0.03)$ & $2.50^{*}(0.03)$ & $2.50^{*}(0.03)$ \\
CSES & $0.13^{*}(0.02)$ & $0.13^{*}(0.02)$ & $0.13^{*}(0.02)$ \\
Siblings & $-0.00(0.01)$ & $-0.01(0.01)$ & $-0.01(0.01)$ \\
CSES $\times$ Siblings & & $-0.01(0.01)$ & $-0.01(0.01)$ \\
SES & & & $0.00(0.02)$ \\
$R^{2}$ & 0.06 & 0.06 & 0.06 \\
$F$ Statistic & $31.16^{*}$ & $21.12^{*}$ & $15.83^{*}$ \\
\hline
\end{tabular}

${ }^{*} p<.001$. Regression coefficients and standard errors (in parentheses). Greed was assessed with the DGS (Seuntjens et al., 2015), and CSES and SES with the Childhood-SES and the SES scale (Griskevicius et al., 2011)

related to greed. This finding is in line with the luxury hypothesis.

The data also again revealed a significant negative correlation between CSES and the number of siblings (i.e., family size), as in Study 1. The data also revealed that males were greedier than females, and that greed was negatively correlated with age. These findings replicate earlier findings (e.g., Krekels \& Pandelaere, 2015; Liu et al., 2019c; Seuntjens et al., 2015; Zeelenberg et al., 2020). Childhood-SES correlated positively and significantly with current SES.

As in Study 1, we tested the competing Scarcity and Luxury hypotheses in a hierarchical multiple linear regression analysis on the relationship between CSES and DGS, moderated by the number of siblings. In the first step we entered centered CSES and number of siblings; in the second step we added the interaction between centered CSES and number of siblings. For exploratory purposes we entered centered SES in the third step. Table 4 displays the results of these analyses.

CSES positively predicted adult greed, replicating Liu et al. (2019c) and Study1, supporting the luxury hypothesis. The number of siblings did not predict adult greed. Contrary to Liu et al., and Study 1 the interaction effect was non-significant, meaning that we did not find that the relationship between CSES and DGS was moderated by number of siblings. The effect of CSES on greed was robust to controlling for both gender and age (see Table 7 in the Appendix). Two participants indicated to have an extremely high number of siblings (i.e., 25 and 26 siblings). Excluding these participants as a robustness check yielded similar results. Furthermore, in our exploratory analysis, we found no additional effect of
SES on adult greed. SES did predict greed when entered as single predictor, $\beta=.05, t(997)=2.91, p=.004$, $F(1,997)=8.49$.

\section{General Discussion}

The aim of our research was to examine the relationship between the economic circumstances at childhood (i.e., growing up poor or wealthy) and adult dispositional greed. In a large study with Chines adolescents Liu et al. (2019c) found support for the Luxury hypothesis, the idea that growing up wealthy would be related to higher levels of dispositional greed in adults (based on initial findings of Poluektova et al., 2015, and Lea et al., 1995). Liu et al. did not find support for the competing Scarcity hypothesis, the idea that growing up poor would be related to higher levels of dispositional greed (based on initial findings by Krekels, 2015, and Chen, 2018). Liu et al. (Liu et al., 2019c, p. 38) stated that "It would be beneficial to test our model in other countries in which the number of children per family is generally more diversified." Thus, we replicated the study in a largescale, representative Dutch sample (i.e., the LISS panel). We further replicated the study in a large-scale U.S. American sample, via Prolific. Compared to the Chinese adolescent sample used by Liu et al. (2019c), both our samples had a larger variety in the number of siblings that people have and came from countries that have a longer history of capitalism, likely resulting in more pronounced differences in wealth experienced when growing up.

Replicating Liu et al. (2019c), we found support for the luxury hypothesis in both of our samples. That is, dispositional greed was positively associated with childhood socioeconomic status, implying that the more people reported growing up wealthy, the greedier they were as adults.

We found a moderating role of number of siblings on the relationship between CSES and greed in our Dutch sample in Study 1, replicating the second finding of Liu et al. (2019c), but we did not find this in the American sample of Study 2. More specifically, Study 1 found that the positive relationship between greed and CSES was stronger for children with few siblings than for children with more siblings. This suggests that when children grow up with a lot of resources and also do not need to share these with their siblings, they might become greedier later in life. This is in line with the resource dilution model, which postulates that the more children there are in a family, the more resources are divided among offspring (Blake, 1981). However, our data also heed caution to interpreting the relation between greed and family size: The relationship disappeared when analyzing only the younger generation, but the interaction effect was present for the older generation. This disappearance might be driven by the decrease in family size over the past decades 
in (Western) European societies. In the American sample in Study 2, the correlation between age and number of siblings was non-significant, and we also did not find a relation between greed and family size in the results of the regression analysis. This difference in findings concerning the role of family size in our Dutch and American samples might be related to a variety of factors. The USA and the Netherlands represent markedly different political systems and policies, and there are personality differences between both countries (Eigenhuis et al., 2015). We will not speculate here about what specifically might be causing the differences found in our studies, but leave it up to future research to delve more specifically into the role of the family make-up when growing up in affecting adult greed. Despite this precaution, we do believe that these results together shed initial light on the origins of greed and on the environmental factors that may contribute to the psychological development of greed.

Contrary to Liu et al. (2019c), our results from Study 1 were not robust to controlling for both gender age (but they were in Study 2). The relationship between greed and age does not seem to be a straightforward one. On the one hand, we did find greed to be negatively correlated with age in both studies, which is consistent with earlier studies on adults cited earlier. On the other hand, Liu et al. found a positive relationship between greed and age, $r(3200)=.14$, $p<.001$. Interestingly, this is consistent with earlier findings of Seuntjens et al. (2016), who also had adolescent participants, and found that age and dispositional greed correlated positively, $r(3899)=.04, p<.05$ These findings fit with a suggestion by Liu et al. (2019c) about an inverted U-shape relationship between greed and age, but our data cannot provide conclusive evidence for such a relationship. Ideally, a future, longitudinal study should investigate the underlying mechanism of differences in greed over the years.

\section{Limitations and Future Research}

The replication of the luxury hypothesis suggests two further questions for research into how childhood experiences are related to adult greed. First is the relationship between greed of parents and their children. Greedy parents might create an environment where greed is the norm. In addition, they might deliberately decide to have fewer children (so that they do not have to share their resources), leaving their children with fewer siblings. Second is the possibility for identification and intervention. Given that dispositional greed is likely to develop at an early age and is associated with various harmful and undesirable outcomes later in life (Liu et al., 2019a; Seuntjens et al., 2016, 2015, 2019; Zeelenberg et al., 2020), Liu et al. (2019b) made a case for a mindful parenting intervention to help adolescents to develop more positive core self-evaluations and reduce adolescent greed. They found that embracing mindful parenting enriches adolescents' self-evaluations, which prevent them from becoming greedy.

In this article, we closely replicated Liu et al. (2019c) and hence, measured CSES with the commonly used scale of Griskevicius et al. (2011). Notably, in several studies subjective assessments of (C)SES were more predictive of decision-making, psychological functioning and health-related factors than more objective indicators (see for example, Adler et al., 2000; Singh-Manoux et al., 2005; Thompson et al., 2020), and empirical evidence has suggested that retrospective reports are accurate (see for example, Brewin et al., 1993; Hardt \& Rutter, 2004). Nevertheless, a subjective retrospective scale, such as CSES, does not necessarily reflect the "objective" SES at time of childhood (e.g., the memories of childhood could be prone to change). Thus, it could be informative to follow Krekels (2015) and re-examine the link between greed and CSES using a more objective operationalization of CSES, such as, parental occupation, parental education, and parental income during childhood. Longitudinal studies could be used to investigate the development of the greedy disposition, and to overcome the limitations of retrospective measurements.

Despite the consistent results regarding the subjective CSES measure and dispositional greed that were found in this research and in Liu et al. (2019c), the relation between current SES and dispositional greed is less clear. CSES is often related to SES: Children from low-SES backgrounds are more likely to become low-SES adults, and vice versa (see for example, Chen \& Miller, 2012; Brady \& Matthews, 2002). Both Krekels (2015) and Seuntjens et al. (2015) found that dispositional greed was unrelated to current income. In the Study 2, we found a correlation between current SES and dispositional greed, but SES had no additional effect when Childhood-SES, number of siblings and their interaction were accounted for. Clearly, more research is needed here.

\section{Conclusion}

To summarize, using two large-scale adult samples from The Netherlands and the USA, we replicated the main finding by Liu et al. (2019c) on the luxury hypothesis of greed. The wealthier children grow-up, the greedier they are in adulthood. In the Dutch sample this was especially if they have fewer, rather than more siblings. In the American sample this was a general effect, independent of the number of siblings. Given the wide-spread relationships between adult greed and a host of economic and psychological outcomes, we believe that these findings are important for our understanding of the early development of economic and social preferences. 


\section{Appendix}

Table 5 Hierarchical regression analyses of number of siblings and childhood socioeconomic status (CSES) on dispositional greed, controlling for gender (step 1-6) and age (step 2, 4, \& 6) $(N=2367)$ in study 1

\begin{tabular}{|c|c|c|c|c|c|c|}
\hline \multirow[b]{2}{*}{ Predictors } & \multicolumn{6}{|c|}{ Dependent Variable $=$ Dispositional Greed } \\
\hline & Step 1 & Step 2 & Step 3 & Step 4 & Step 5 & Step 6 \\
\hline Constant & $\begin{array}{l}1.95^{*} \\
(0.02)\end{array}$ & $\begin{array}{l}1.94 * \\
(0.02)\end{array}$ & $\begin{array}{l}1.95^{*} \\
(0.02)\end{array}$ & $\begin{array}{l}1.94 * \\
(0.02)\end{array}$ & $\begin{array}{l}1.94 * \\
(0.02)\end{array}$ & $\begin{array}{l}1.94 * \\
(0.02)\end{array}$ \\
\hline CSES & & & $\begin{array}{l}0.04^{*} \\
(0.01)\end{array}$ & $\begin{array}{l}-0.00 \\
(0.01)\end{array}$ & $\begin{array}{l}0.04 * \\
(0.01)\end{array}$ & $\begin{array}{l}-0.00 \\
(0.01)\end{array}$ \\
\hline Siblings & & & $\begin{array}{l}-0.03^{*} \\
(0.01)\end{array}$ & $\begin{array}{l}-0.00 \\
(0.01)\end{array}$ & $\begin{array}{l}-0.04^{*} \\
(0.01)\end{array}$ & $\begin{array}{l}-0.00 \\
(0.01)\end{array}$ \\
\hline CSES $\times$ Siblings & & & & & $\begin{array}{l}-0.02 * \\
(0.00)\end{array}$ & $\begin{array}{l}-0.01^{\dagger} \\
(0.00)\end{array}$ \\
\hline \multicolumn{7}{|l|}{ Control Variables } \\
\hline Gender & $\begin{array}{l}0.19^{*} \\
(0.03)\end{array}$ & $\begin{array}{l}0.22 * \\
(0.03)\end{array}$ & $\begin{array}{l}0.19^{*} \\
(0.03)\end{array}$ & $\begin{array}{l}0.22 * \\
(0.03)\end{array}$ & $\begin{array}{l}0.19^{*} \\
(0.03)\end{array}$ & $\begin{array}{l}0.22 * \\
(0.03)\end{array}$ \\
\hline Age & & $\begin{array}{l}-0.01^{*} \\
(0.00)\end{array}$ & & $\begin{array}{l}-0.01^{*} \\
(0.00)\end{array}$ & & $\begin{array}{l}-0.01^{*} \\
(0.00)\end{array}$ \\
\hline$R^{2}$ & 0.02 & 0.16 & 0.04 & 0.16 & 0.05 & 0.16 \\
\hline$F$ Statistic & $44.57 *$ & 229.10* & $32.56^{*}$ & 114.50 & $28.78^{*}$ & $92.24 *$ \\
\hline
\end{tabular}

$\dagger p<.1 ; * p<.001$. Regression coefficients and standard errors (in parentheses). Greed was assessed with the DGS (Seuntjens et al., 2015). CSES with the Childhood-SES scale (Griskevicius et al., 2011). Gender is coded, $0=$ female, $1=$ male
Table 6 Hierarchical regression analysis of number of siblings and childhood socioeconomic status (CSES) and their interaction (step 2) for the tounger generation (Age $\leq 35$, $N=455$ ) and the older generation (Age $>35, N=1912)$ in study 1

\begin{tabular}{lllll}
\hline & \multicolumn{4}{l}{ Dependent Variable $=$ Dispositional Greed } \\
\cline { 2 - 5 } & Age $\leq 35$ & Age $>35$ & \\
\hline Predictors & Step 1 & Step 2 & Step 1 & Step 2 \\
Constant & $2.42^{* * *}(0.05)$ & $2.43^{* * *}(0.05)$ & $1.95^{* * *}(0.01)$ & $1.94^{* * * *}(0.01)$ \\
CSES & $0.06^{*}(0.03)$ & $0.07 *(0.03)$ & $-0.00(0.01)$ & $0.00(0.01)$ \\
Siblings & $-0.02(0.03)$ & $-0.02(0.03)$ & $-0.02^{* *}(0.01)$ & $-0.02^{* * *}(0.01)$ \\
CSES $\times$ Siblings & & $0.01(0.02)$ & & $-0.01^{*}(0.00)$ \\
$R^{2}$ & 0.01 & 0.01 & 0.01 & 0.01 \\
$F$ Statistic & $3.18^{*}$ & $2.15^{\dagger}$ & $5.39^{* *}$ & $5.82^{* * *}$ \\
\hline
\end{tabular}

Note. $* * * p<.001, * * p<.01, * p<.05, \dagger p<.1$. Regression coefficients and standard errors (in parentheses). Greed was assessed with the DGS (Seuntjens et al., 2015). CSES with the Childhood-SES scale (Griskevicius et al., 2011) 
Table 7 Hierarchical regression analysis of number of siblings and childhood socioeconomic status (CSES) on dispositional greed, controlling for gender and age $(N=976)$ in study 2

\begin{tabular}{llll}
\hline \multirow{2}{*}{ Predictors } & \multicolumn{3}{l}{ Dependent Variable $=$ Dispositional Greed } \\
\cline { 2 - 4 } & Step 1 & Step 2 & Step 3 \\
\hline Constant & $2.37^{*}(0.04)$ & $2.39^{*}(0.04)$ & $2.39^{*}(0.04)$ \\
CSES & & $0.13^{*}(0.02)$ & $0.13^{*}(0.02)$ \\
Siblings & & $-0.00(0.01)$ & $-0.00(0.01)$ \\
CSES $\times$ Siblings & & & $-0.01(0.01)$ \\
Control variables & & & \\
Gender & $0.28^{*}(0.06)$ & $0.23^{*}(0.05)$ & $0.23^{*}(0.05)$ \\
Age & $-0.01^{*}(0.00)$ & $-0.01^{*}(0.00)$ & $-0.01^{*}(0.00)$ \\
$R^{2}$ & 0.04 & 0.09 & 0.09 \\
$F$ Statistic & $19.66^{*}$ & $24.29 *$ & $19.53^{*}$ \\
\hline
\end{tabular}

Note. * $p<.001$. Regression coefficients and standard errors (in parentheses). Greed was assessed with the DGS (Seuntjens et al., 2015). CSES with the Childhood-SES scale (Griskevicius et al., 2011)

Data Availability The data that support the findings of Study 1 are freely available from the LISS panel via https://www.dataarchive.lissd ata.nl/study_units/view/889 after registration. The dataset generated during and/or analysed during the Study 2 are available in the Research Box repository, https://researchbox.org/177.

Funding Data collection was made possible by an ODISSEI (Open Data Infrastructure for Social Science and Economic Innovations) LISS Panel Access grant "Greed, self-interest and socio-economic success" awarded to S. M. Breugelmans, M. Zeelenberg and K. Hoyer.

\section{Declaration}

Ethics Approval All study procedures were approved by the ethics board of the School of Social and Behavioral Sciences at Tilburg University, EC-2018.EX187.

Informed Consent Was obtained from all individual participants by LISS in study 1 and by the researchers in study 2 .

\section{Competing Interests None.}

Open Access This article is licensed under a Creative Commons Attribution 4.0 International License, which permits use, sharing, adaptation, distribution and reproduction in any medium or format, as long as you give appropriate credit to the original author(s) and the source, provide a link to the Creative Commons licence, and indicate if changes were made. The images or other third party material in this article are included in the article's Creative Commons licence, unless indicated otherwise in a credit line to the material. If material is not included in the article's Creative Commons licence and your intended use is not permitted by statutory regulation or exceeds the permitted use, you will need to obtain permission directly from the copyright holder. To view a copy of this licence, visit http://creativecommons.org/licenses/by/4.0/.

\section{References}

Adler, N. E., Epel, E. S., Castellazzo, G., \& Ickovics, J. R. (2000). Relationship of subjective and objective social status with psychological and physiological functioning: Preliminary data in healthy white women. Health Psychology, 19(6), 586-592. https://doi.org/ 10.1037/0278-6133.19.6.586

Armsden, G. C., \& Greenberg, M. T. (1987). The inventory of parent and peer attachment: Individual differences and their relationship to psychological well-being in adolescence. Journal of Youth and Adolescence, 16, 427-454.

Blake, J. (1981). Family size and the quality of children. Demography, 18(4), 421-442.

Bloch, A. P. (1984). A book of Jewish ethical concepts. Ktav Publishing House Inc..

Brady, S. S., \& Matthews, K. A. (2002). The influence of socioeconomic status and ethnicity on adolescents' exposure to stressful life events. Journal of Pediatric Psychology, 27(7), 575-583. https://doi.org/10.1093/jpepsy/27.7.575

Brewin, C. R., Andrews, B., \& Gotlib, I. H. (1993). Psychopathology and early experience: A reappraisal of retrospective reports. Psychological Bulletin, 113(1), 82-98. https://doi.org/10.1037/ 0033-2909.113.1.82

Brumbach, B. H., Figueredo, A. J., \& Ellis, B. J. (2009). Effects of harsh and unpredictable environments in adolescence on development of life history strategies. Human Nature, 20(1), 25-51. https://doi.org/10.1007/s12110-009-9059-3

Chen, B.-B. (2018). An evolutionary life history approach to understanding greed. Personality and Individual Differences, 127(February), 74-78. https://doi.org/10.1016/j.paid.2018.02.006

Chen, E., \& Miller, G. E. (2012). Shift-and-persist strategies why low socioeconomic status isn't always bad for health. Perspectives on Psychological Science, 7(2), 135-158. https://doi.org/10.1177/ 1745691612436694

Eccles, D. W., Ward, P., Goldsmith, E., \& Arsal, G. (2013). The relationship between retirement wealth and householders' lifetime personal financial and investing behaviors. Journal of Consumer Affairs, 47(3), 432-464. https://doi.org/10.1111/joca.12022

Eigenhuis, A., Kamphuis, J. H., \& Noordhof, A. (2015). Personality differences between the United States and the Netherlands: The influence of violations of measurement invariance. Journal of Cross-Cultural Psychology, 46(4), 549-564. https://doi.org/10. $1177 / 0022022115570671$

Greenfeld, L. (2001). The spirit of capitalism: nationalism and economic growth. Harvard University Press.

Griskevicius, V., Ackerman, J. M., Cantú, S. M., Delton, A. W., Robertson, T. E., Simpson, J. A., Thompson, M. E., \& Tybur, J. M. (2013). When the economy falters, do people spend or save? Responses to resource scarcity depend on childhood environments. Psychological Science, 24(2), 197-205. https://doi.org/ 10.1177/0956797612451471

Griskevicius, V., Delton, A. W., Robertson, T. E., \& Tybur, J. M. (2011). Environmental contingency in life history strategies: The influence of mortality and socioeconomic status on reproductive timing. Journal of Personality and Social Psychology, 100(2), 241-254. https://doi.org/10.1037/a0021082.Environmental

Hardt, J., \& Rutter, M. (2004). Validity of adult retrospective reports of adverse childhood experiences: Review of the evidence. Journal of Child Psychology and Psychiatry, 45(2), 260-273. https://doi. org/10.1111/j.1469-7610.2004.00218.x 
Hoyer, K., Zeisberger, S., Breugelmans, S. M., \& Zeelenberg, M. (2021). Greed and individual trading behavior in experimental asset markets. Decision, 8(2), 80-96. https://doi.org/10.1037/dec0000149

Krekels, G. (2015). Essays on dispositional greed. Ghent University. https://biblio.ugent.be/publication/5956382

Krekels, G., \& Pandelaere, M. (2015). Dispositional greed. Personality and Individual Differences, 74, 225-230. https://doi.org/10. 1016/j.paid.2014.10.036

Lea, S. E. G., Webley, P., \& Walker, C. M. (1995). Psychological factors in consumer debt: Money management, economic socialization, and credit use. Journal of Economic Psychology, 16(4), 681-701. https://doi.org/10.1016/0167-4870(95)00013-4

Li, W., Wang, H., Xie, X., \& Li, J. (2019). Neural mediation of greed personality trait on risk preference. ELife, 8, 1-15. https://doi.org/ 10.7554/eLife.45093

Li, X., Dang, J., Liu, Liang, Y., Wei, C., \& Gu, Z. (2021). Are greedy individuals more corrupt? Current Psychology. https://doi.org/10. 1007/s12144-021-01415-1

Liu, Z., Sun, X., Ding, X., Hu, X., Xu, Z., \& Fu, Z. (2019a). Psychometric properties of the Chinese version of the dispositional greed scale and a portrait of greedy people. Personality and Individual Differences, 137, 101-109. https://doi.org/10.1016/j.paid.2018.08.012

Liu, Z., Sun, X., Guo, Y., \& Luo, F. (2019b). Mindful parenting inhibits adolescents from being greedy : The mediating role of adolescent core self-evaluations. Current Psychology. https://doi.org/10.1007/ s12144-019-00577-3

Liu, Z., Sun, X., \& Tsydypov, L. (2019c). Scarcity or luxury: Which leads to adolescent greed? Evidence from a large-scale Chinese adolescent sample. Journal of Adolescence, 77, 32-40. https://doi. org/10.1016/j.adolescence.2019.10.002

Mittal, C., Griskevicius, V., Simpson, J. A., Sung, S., \& Young, E. S. (2015). Cognitive adaptations to stressful environments: When childhood adversity enhances adult executive function. Journal of Personality and Social Psychology, 109(4), 604-621. https:// doi.org/10.1037/pspi0000028

Mussel, P., Reiter, A. M. F., Osinsky, R., \& Hewig, J. (2015). State- and trait-greed, its impact on risky decision-making and underlying neural mechanisms. Social Neuroscience, 10(2), 126-134. https:// doi.org/10.1080/17470919.2014.965340

Poluektova, O., Efremova, M., \& Breugelmans, S. M. (2015). Poverty and psychology. In Higher School of Economics Research Paper No. WP BRP. https://www.hse.ru/data/2015/12/04/1080734458/ 49PSY2015\%20(2).pdf
Seuntjens, T. G., Van de Ven, N., Zeelenberg, M., \& Van der Schors, A. (2016). Greed and adolescent financial behavior. Journal of Economic Psychology, 57, 1-12. https://doi.org/10.1016/j.joep. 2016.09.002

Seuntjens, T. G., Zeelenberg, M., Van de Ven, N., \& Breugelmans, S. M. (2015). Dispositional greed. Journal of Personality and Social Psychology, 108(6), 917-933. https://doi.org/10.1037/ pspp0000031

Seuntjens, T. G., Zeelenberg, M., Van de Ven, N., \& Breugelmans, S. M. (2019). Greedy bastards: Testing the relationship between wanting more and unethical behavior. Personality and Individual Differences, 138, 147-156. https://doi.org/10.1016/j.paid.2018. 09.027

Singh-Manoux, A., Marmot, M. G., \& Adler, N. E. (2005). Does subjective social status predict health and change in health status better than objective status? Psychosomatic Medicine, 67(6), 855-861. https://doi.org/10.1097/01.psy.0000188434.52941.a0

Thompson, D. V., Hamilton, R. W., \& Banerji, I. (2020). The effect of childhood socioeconomic status on patience. Organizational Behavior and Human Decision Processes, 157, 85-102. https:// doi.org/10.1016/j.obhdp.2020.01.004

Tickle, P. A. (2004). Greed: The seven deadly sins. Oxford University Press.

Van de Vijver, F. J. R., \& Leung, K. (1997). Methods and data analysis for cross-cultural research. Sage.

Veselka, L., Giammarco, E. A., \& Vernon, A. (2014). The dark triad and the seven deadly sins. Personality and Individual Differences, 67, 75-80. https://doi.org/10.1016/j.paid.2014.01.055

Zeelenberg, M., Seuntjens, T. G., Van de Ven, N., \& Breugelmans, S. M. (2021). Dispositional greed scales. European Journal of Psychological Assessment. https://doi.org/10.1027/1015-5759/ a000647

Zeelenberg, M., Seuntjens, T. G., Van de Ven, N., \& Breugelmans, S. M. (2020). Enough is never enough: Overearning as a manifestation of dispositional greed. Personality and Individual Differences, 165, 110155. https://doi.org/10.1016/j.paid.2020.110155

Zhang, W., \& Xiang, Y. (2021). Reliability, validity and invariance of the moral sensitivity questionnaire in the China general social survey. Current Psychology. https://doi.org/10.1007/ s12144-020-01246-6

Publisher's note Springer Nature remains neutral with regard to jurisdictional claims in published maps and institutional affiliations. 